present more stable constellations. ${ }^{1}$ We do not doubt that vital force is a mode of motion due to the presence of atoms in labile positions in the albuminous substance. The motion ceases when there occurs a migration of the labile atoms to some stable position. The aldehydes give us fine illustrations of labile combinations and stable rearrangements in other allied substances.

The question now arises, can we chemically demonstrate that the albuminous substance formed by synthesis in plants is-even before it has become protoplasmdifferent from ordinary albumen? It was known long ago that the juice of plants-that is the aqueous solution in the vacuoles of the cells-contains albumen, but it was thought to be ordinary albumen. It is easy to prove that this is not the case. ${ }^{2}$

On treating living plant cells with dilute solutions of ammonia or organic bases or their salts, remarkable changes are observed. These consist either in the formation of numerous minute granules as is the case on the application of most of the bases, or in the production of little globules flowing together to make relatively large drops of a substance of high refractory power, as is the case on the application of weak bases like caffein or antipyrin. $^{3}$ These latter two bases in weak solution do not injuriously affect the protoplasm itself, since the cells will keep alive for a number of days in a $0^{\circ} 5$ per cent. solution of these bases; the cells are, however, soon killed by other bases and their salts. The granules and globules formed in the living cells by the action of caffein have been called by Bokorny and myself Proteosomes. They give the principal reactions of albuminous bodies, but contain in most cases an admixture of small quantities of lecithin and tannin. These admixtures, however, can be removed by cultivating the objects (the alga, Spirogyra, for instance) in solutions rich in nitrates. If now by such cultivation the tannin has been removed and the proteosomes then produced by treatment with caffein, we can observe that these albuminous proteosomes are capable of reducing silver from even highly diluted alkaline solutions. This property is lost after treatment with dilute acids as well as after the death of the cells. ${ }^{4}$ In these cases the proteosomes become hollow and turbid, their substance appearing to coagulate and shrink.

There are thus experimental grounds for the conclusion that not only the organized albumen of the living protoplasm, but also the albumen dissolved in the vacuolesthe unorganized albumen-is a different substance from the ordinary albumen, which is present in dead cells. We may sum up the line of argument as follows :-

I. Bases act upon the albumen of living cells; not, however, upon that of dead cells, nor upon ordinary dissolved albumen.

II. The action may be observed microscopically to take place in the case of various vegetable objects in the liquid portion of the protoplasm itself as well as in the vacuoles. This can be specially well observed with the alga Spirogyra when treated with caffein.

III. The granules and globules into which the active albumen aggregates by the action of bases--called by us proteosomes - have the property of reducing dilute silver solutions in the absence of light, and lose this property by the action of acids.

IV. The active albumen in its most unchanged condition can be made visible by caffein or antipyrin, two bases that do not act as serious poisons to the cells. Living cells containing proteosomes, brought out by caffein

I Many examples can be cited from organic chemistry; for instance, the rapid change of the diamidoaceton as [soon as it is liberated from its salt (Berichte d. Deutschen Chem. Ges. 25, 1563). Compare also the article, Chemical Motions," Biolog. Centralblatt ix. N. I6.

O. Loew und Th. Bokorny, Biolog. Centralblatt xi. $x$.

3 These globules closely resemble the aggregated masses that Darwin observed after irritation of leaves of Drosera.

4 The proteosomes produced by ammonia and various other bases preserve this property for a much longer time after the death of the cell than those produced by caffein or antipyrin.

NO. I I95, VOL. 46] when placed in distilled water regain their original condition, the proteosomes become gradually dissolved again (rapidly at $25^{\circ} \mathrm{C}$.), and a new application of caffein will now make them reappear.

V. If proteosomes are produced by caffein or antipyrin, and the death of the cells is then caused by ether vapour, \&c, it may be easily observed that soon after the death of the protoplasm the proteosomes of the vacuoles are also changed in their optical and chemical properties; they become turbid and hollow, they coagulate, and they lose their property of being resoluble in distilled water.

O. LOEW.

\section{DISCOVERY OF A FIFTH SATELLITE TO JUPITER.}

I J January of the year I6ro Galileo, at Padua, in Italy, discovered four satellites revolving round Jupiter, and though more than 282 years elapsed in the interval, from that time to August, 1892 , no additional satellites were detected near this planet, and astronomers naturally inferred that no others existed. The fact that Jupiter possessed four satellites has become familiar to every schoolboy, for it has been repeated in all the astronomical text-books published during nearly three centuries. Few people therefore could have inasined that the statement would ever be controverted or rendered wntenable by new discoveries. In regard to the more distant planets Uranus and Neptune, there was every prospect of additional satellites being detected, but with Jupiter the circumstances were somewhat different. The four satellites were so bright and so palpably visible in very small telescopes that it was scarcely thought possible that another existed small enough to remain unseen. Moreover, there was a significant agreement in the relatively increasing numbers of the satellites surrounding the planets Mars, Jupiter, and Saturn. Mars was known to have two satellites, Jupiter four, and Saturn eight, the number doubling itself with each step outward from the sun, and it was considered probable that the harmony of the series would not be disturbed.

Now, however, the astronomical world has been excited by the announcement that a new satellite has been discovered in attendance on Jupiter, and that its dis. tance from the centre of the planet is 112,400 miles, and its period of revolution I7 hours 36 minutes. The discovery was effected by Prof. Barnard, of the Lick Observatory on Mount Hamilton in California, and, as he has already proved himself a very acute observer, especially of comets, and as he has the occasional use of what is supposed to be the most powerful telescope hitherto constructed, there is no good reason to discredit the intelligence.

People will be obviously led to ask how this new satellite managed to evade detection during nearly three centuries of diligent telescopic research. How was it that one at least of the host of observers who have studied this plane and his circling moons by means of powerful glasses, did not sight the tiny orb which has now revealed itself to the watchful American astronomer? We imagine that the chief reason for this want of success is to be found in the fact that the new orb is not brighter than the thirteenth magnitude, and that, being situated close to its primary, it would therefore, in ordinary instruments, be quite obliterated in the surrounding glare. But it is perhaps rather singular that it was not detected by its shadow, which would be projected on the disc of Jupiter whenever the satellite passed between the planet and the earth, and this would be of daily occurrence. At such a time the shadow would appear as a small, black, circular spot moving rapidly from east to west across the disc, and with greater apparent velocity than the visible 
markings. And it is quite possible that the shadow has been observed on more than one occasion, but mistaken for an ordinary spot on the surface of Jupiter.

A curious fact in connection with the new satellite is its diminutive size as compared with the four others discovered by Galileo in I6IO. But there is a similar disparity in the dimensions of the satellites of Saturn, and in proof of this we have only to compare the bright Titan with the excessively faint Mimas and Hyperion. Small as it is, however, it is certain that this new satellite of Jupiter is much larger than either of the two abnormally minute moons of Mars.

American astronomers are to be congratulated on this important discovery. Scientific activity in the United States has been rapidly developing in recent years, and this has been strikingly exemplified in the wide and attractive domain of astronomy. W. F. DENNING.

\section{NOTES.}

THe French As sociation for the Advancement of Science is holding at Pau its twenty-first annual meeting. The meeting began on Saturday last, when the members of the Association were cordially welcomed to Pau by the Mayor. The President, M. Collignon, delivered an address on the science and art of the engineer.

THE autumn meetings of the Iron and Steel Institute, under the presidency of Sir Frederick Abel, began at St. George's Hall, Liverpool, on Tuesday. At the o pening meeting the President announced that the Council had elected $\mathrm{Mr}$. Windsor Richards as his successor.

WE are glad to announce that a new Biological Laboratory is about to be established in the Calcutta Zoological Gardens. Babu Joy Gobinda Law, a member of one of the wealthy native families of Bengal, has offered R. 15,000 for the buildings and fittings of this institution. The primary object for which the Laboratory is founded is to investigate the action of snakepoison, and to discover, if possible, an antidote. The Laboratory will, however, also be used for anatomical and pathological researches, for which the rich material afforded by the animals in the gardens will be available.

THE Marine Biological Labo ratory at Wood Hole, U.S., has been more successful this summer than in any previous year. During its season of work it had a corps of seventeen officers, instructors, and assistants, and an attendance of thirty-eight investigators and sixty-two elementary students.

With the designation of the Hopkins Seaside Laboratory, a marine biological laboratory has been established at Pacific Grove, California. We learn from the Botanical Gazette that, through the generosity of the Pacific Improvement Company, a piece of land has been furnished, and a sum granted sufficient to erect a plain frame building; and, by the liberality of $\mathrm{Mr}$. Timothy Hopkins, provision is made for the equipment of the building, and for the further continuation and extension of the enterprise. An elementary course of lectures on marine botany was to be given during the present season.

THE weather during the past week was very fine and bright over the southern and eastern portions of the United Kingdom, until near the close of the period, when the type entirely changed, anil thunderstorms, accompanied by heavy rain, occurred generally, but in the north and west the conditions were throughout far less settled. Cyclonic disturbances arrived on our coasts from the Atlantic with considerable frequency, and although they were for the most part slight and shallow, and unaccompanied by much wind, they were productive of a considerable quantity of rain. An important disturbance passed to the north of Scotland on NO. I T95. VOL. 467
Thursday night and during Friday, and was accompanied by strong gales on our north-west and north coasts. Temperatures were high for the season over the greater part of England, and on Monday the day readings in places were higher than at any time during the month, the shade thermometer registering $72^{\circ}$ in London. Some nights, however, were exceptionally cold, the shade minimum between Saturday and Sunday falling to within one degree of the freezing point in the eastern part of England, while there was a sharp frost on the ground open to the sky. The Weekly Wiather Report, issued on the 1 7th inst., shows that the rainfall exceeded the mean in the north and west of Scotland and in the north of Ireland. In all the other parts of the United Kingdom there was a deficit; in most of the English districts the fall was very slight.

THE Report of the Meteorological Commission for the year i 89 I states that complete, or nearly complete, meteorological observations have been received from forty-nine stations, and that observations of rainfall have been furnished from 320 stations; the instruments are usually supplied by the Commission. The Report contains diagrams showing the mean monthly rainfall corrected to date at thirty-three stations, together with the abnormal falls in the years I888 and 1891 . The rainfall in $189 \mathrm{r}$ has been excessive, especially over the eastern part of the colony and over the Orange Free State, where at some places it exceeded 12 inches above the average. The observer at Phillipolis states that hardly a farmer in that district but has lost one-third of his sheep, owing to the continued wet, and in some places the farmers have had to vacate their homes in consequence of the weather.

THe "Pilot Chart of the North Atlantic Ocean" for Septem. ber contains tracks of the drift of the two parts of the derelict ship Fred. B. Taylor, which was cut in two by a collision on June 22, in lat. $40^{\circ} 19^{\prime}$ N., long. $68^{\circ} 33^{\prime} \mathrm{W}$. The forward and after parts separated, and drifted in entirely different directions, in a manner which is quite unprecedented in the history of shipwrecks. The after end was evidently influenced more by wind than the bow portion; the latter pursued a south-westerly course, which was attributable largely to the cold southerly current between the American coast and the Gulf Stream, and on August 26 had drifted to lat. $38^{\circ} 40^{\prime}$, long. $73^{\circ} 15^{\prime}$. The stern part took a direct northerly course until July 17 , when it was ten miles north-west of Matinicus 1sland, whence it took a westerly course, and was cast ashore on August 7 on Wells Beach, near Cape Porpoise.

THE first annual convention of the American Association of State Weather Services was held at Rochester, N.Y., on August 15 and 16 , in conjunction with the meeting of the American Association for the Advancement of Science, and was largely attended by representatives of the various States. The subject of thermometer exposure was discussed, and a committee was appointed to consider the most suitable form of shelter and manner of exposure to be adopted throughout the country. It was resolved that means should be deduced from self-registering instruments wherever practicable, in preference to the method of using eye observations. An interesting paper was read by W. L. Moore, of Wisconsin, on the forecasting of thunderstorms ; and the question of the best methods of signalling weather forecasts, whether by flags, semaphores, spherical bodies hoisted on a staff, \&c., was freely discussed, and a committee was appointed to report upon the subject at an early date. It was decided that each State service should have a separate exhibit at the World's Fair at Chicago, and not to have the exhibits collected in the building for the use of the United States Weather Bureau.

LAST year an Aino in the western part of the island of Yezo caught two bears, one of which was perfectly white. This 